\title{
In Becoming EFL Writing Teacher: a Diary Study
}

\author{
Gaston Soehadi \\ English Department, Faculty of Letters, Petra Christian University, \\ Surabaya, Indonesia \\ e-mail: gaston@telkom.net
}

\begin{abstract}
To improve teaching quality, teachers need a tool to help them reflect and evaluate their teaching decisions and actions. Teachers can always rely on schools to do such a job, but they can also use a personal and professional teaching diary as a means to do a self-analysis and evaluation. This article reports the practice of my using the teaching diary as a writing teacher as a means to help me look beyond and reflect on my teaching routines
\end{abstract}

Key words: teaching diary, reflection, essay

Writing plays an important role which speaking cannot do in fulfilling our communicative needs. According to Halliday (1985, pp. 40-41) writing culture serves the following functions: for action (public signs), for social contact (letters, postcards), for information (newspapers, magazines) and for entertainment (film, poetry, songs). The teaching of writing is aimed at developing one's ability to function effectively in such written language contexts. In foreign language class such as English as Second Language (ESL) or English as Foreign Language (EFL), students learn to write to organize and communicate their thoughts in the target language. Academic writing as a specific writing genre and part of English for Academic Purpose (EAP) was introduced in 1970s in English speaking countries where non native speakers of English came to study at universities. Through EAP program, students learn to function for various communicative purposes in academic discourse in English.

\section{PERSONAL TEACHING DIARY AS A TOOL FOR REFLECTI- ON}

Teaching essay writing is a fact for teachers involved in EAP writing course. In a writing class, students do a small research and write it down, making use of information obtained from journals, books, reports, etc. 
There are two kinds of research writing that students usually do: the "report research paper" and "argumentative research paper" (Menasche, 1997, p. 2). The former type belongs to "information reports" in which students search to find and record facts when required. The information report tasks ask students to classify and describe the world phenomenon. The latter type of research writing, on the other hand, not only requires students to collect and describe the data, but also critically analyzes it and argues on a problem. The research writing class prepares and engages students into research activities (although it is minor) such as generating research ideas, finding resources in library, taking notes, making bibliography, developing outline and thesis, drafting and revising the paper; students also do a small field research if it is necessary. The most important thing, at the end of the day, is how to communicate what they have got into a good piece of writing. The fact is that while the research writing class is the advance level of the academic writing, many students in my writing class still encounter some basic writing difficulties such as on how to generate a research topic or how to make a thesis statement. It can take weeks before students can firmly decide on a topic that they really want to write. Another problem is the fact that the idea of research writing is new to students, and this becomes the teacher's responsibility to introduce it to them in the class.

As an EFL teacher of writing, I should help each student dealing with the basic writing problems and research content. I feel that these are not easy things to do, especially when I have many students who need my individual help in the class. My previous teaching experience in research writing class taught me that I should pay more attention to and get involved in students' research writing process if I want to see a better class result at the end of the semester. To help me making such an improvement happen, I have kept a personal teaching diary or journal since last year as a means of studying my teaching and everything that is related to it. The use of a personal diary as a means of reflecting on one's own teaching is wellestablished in the research of teacher education. This diary study is "a first person account of a language learning or teaching experience, documented through regular, candid entries in a personal journal and then analyzed for recurring patterns or salient events” (Bailey, 1990, p. 215).

A personal teaching diary is a tool to observe one's teaching beyond the teaching routine and because of its candid nature, it can provide its user with a personal look at the classroom world and might be the one which was never expected before. Porter et al. (1990) said about the use of personal diary for teachers-in-preparation program: 
The journal encourages students to go beyond learning course content in isolation and to strive to link this information to theories and knowledge beyond the particular assignment and the particular procedure. The journal thus enables students to develop a professional approach toward learning and to write as members of the larger language learning community. In sum, it teaches them to do what we do as professionals - to work to integrate new ideas with what we already know and to talk with each other as we do so. (p. 240)

A personal teaching diary thus helps teachers to relate experience to what they are doing. It becomes a tool to create an inner self-dialogue as a professional working within a field and as a student who needs a place to express what he thinks and feels. A teaching diary can become a personal room where one can do "a critical reflection-in-action” (Schon (1987, p. 29). On the idea of reflection, Kemmis (1986) states that:

Reflection is not just an individual, psychological process. It is an action oriented, historically-embedded, social and political frame, to locate oneself in the history of a situation, to participate in a social activity, and to take sides on issues. Moreover the material on which reflection works is given to us socially and historically; through reflection and the action which it informs, we may transform the social relations which characterizes our work and our working situation. (p. 5)

Kemmis stresses a fact that reflection is not equal to a passive action done by one who wants to understand about his doings. Reflection is more than just an attempt to evaluate purposes and consequences of one's own action in daily life. It is a social and political act in which one takes a decision about his position in a society. The author further said that actions produced through true reflections can actually affect and change one's social relations. Reichmann (2005) argues that through a focused reflection, teachers can redefine "who they are, what they do, and why they do what they do as teachers" (p. 126). Reichmann makes a point on the fact that teachers should be proactive in re-examining their teaching philosophy. By being a reflective practitioner, a teacher will be critical-in the positive sense - towards his or her teaching, and aware of the fact that "as a second language teacher, he is both the producer and creator of his own history” (Bartlett, 1990, p. 206). 
Research on the use of a personal diary as a means of teaching and learning has been widely known. Gorman (1998) uses his personal teaching diary to implement changes and what worked. In his journal, he specifies on four areas of concern in his teaching: creating system of peer response, providing an essay structure, improving student's essay details by using asterisk and increasing effectiveness in correcting student's essays. On the advantages of keeping a personal diary, Gorman states:

The journal can help teachers immensely as long as teachers can be self-critical. The great dilemma for research purposes is that reflective practitioners are their own evaluators. Nevertheless, if teachers can be honest with themselves, not too critical or excessively lenient, positive change can result. (p. 442)

Gorman suggests that every time teachers make a reflection, they need to follow it up with an action because that is where reflection meets its goals. In that way, a personal and professional diary can become a tool of literacy development and learning. Boonmoh (2005) through a study of his teaching diary examines the changes of his attitude when he had to teach a large foundation English class (84 first-year students). His diary specifically studies the problems that emerged in his class and how he worked on the solution to the problems. The result of his analysis showed that his attitude towards teaching a large class changed from negative to positive, and this could be seen from the way he dealt with the class problems. Through his reflection, Boonmoh finds that "a large class is not problematic in itself but it is the teacher's perceptions, attitudes, and the nature of activities that influence the student's opportunities for learning English” (p.18). This shows a positive example of keeping a professional diary. Carroll (1994) implements the use of learning diary to his adult students in his professional immigrant class. He mainly develops the use of journal into a dialogue journal because he believes that lessons are learned through interactions among student-student and student-teacher. Another thing is that through a dialogue journal, learners can theorize themselves and find ways to make self-improvement. On the use of diary as a tool of learning, Carroll cites Mezirow (1991) who argues that:

a learning diary can particularly decrease learner's dependency on teachers, develop learner's understanding of how to use learning resources, especially the experience of others, help learners define their own learning needs and assume responsibility for setting their own objectives, and foster learner's ability to make decisions about learning path, thereby expanding their range of options (1994, p. 20) 
A learning diary can teach students to be an independent learner as it gives them a means of becoming an observer for their own learning process. Numrich (1996) and Reichmann (2001) use the diary to study problems that are faced by the pre-service teachers in their first year of teaching. Alexander (2001), and Carroll and Mchawala (2001) find that their ESL students, through the use of personal learning diary, are able to rediscover their ability to express their own ideas and perspectives in academic writing. Norton (2000) investigates the life of women immigrant in Canada through their diary writing. It turns out that these women's diaries are useful to reveal a picture in which they have to struggle to learn English and new culture in their new adopted country.

In this article, I report on the use of my teaching diary for my writing class. The writing class that I taught last semester was two research writing classes consisting of twenty (class A) and twenty-four (class B) students. They were required to write a long argumentative research essay, selecting a research topic from the following fields: literature, linguistics/applied language studies and cultural studies. As suggested by Richards and Lockhart (1995) and my previous class experience, I focused my teaching diary on the following teaching problems in my class: generating ideas, writing thesis statement, structuring the essay, and writing conferences. By keeping a personal teaching diary, I would like to study and understand the problems that emerged in class, the solutions, the reasons, and my personal feeling about the class and how the student's essays were scored; in general, I wanted to see how responsive I was to my student's needs.

\section{REFLECTIONS}

It is important to study what a teacher believes about teaching and learning if one wants to understand his classroom's decisions and actions. The teacher's decisions and actions are not only guided by school curriculum, but also by personal beliefs about what works best in his class (Richards \& Lockhart, 1995, p. 29). More than any other, it is the teacher's beliefs about teaching and learning that is crucial in every classroom activity because he is actually the main actor who bridges the gap between the curriculum and students. There are some sources where researchers can study the teacher's belief on teaching and learning: "teacher's own experience as a learner, experience of what works best, established teaching practice, teacher's personality factors, educationally based or research-based principles and principles derived from an approach or method" (p. 31). 


\section{MY STUDENTS’ PROBLEMS IN MY WRITING CLASS}

\section{Generating Ideas}

Getting ideas for research paper is generally the first problem that students in my research writing class have to face. The problem seems to start from a fact that research topics is not the same as the kinds of topics students have in the previous classes. If they could pick up personal topics in the previous level writing classes, the research writing class required them write topics related to the core subjects at English Department such as literature, linguistics or language studies and culture; its purpose is to engage learners into the core disciplines that they will study at the department. My students did have difficulty when they had to think of a topic that represented one of these subjects. They came and asked: "Sir, what should I write? I don't know which one works for me, is writing a literature topic easier than linguistics? Can I change the subject if I find what I am doing now is too difficult?" To these questions, I suggested them to keep a journal and try some free writings on general ideas and which might become their research topics. The diary could also be a place for them to make some reflections on what they had done that was related to writing. They might tell their writing experiences outside the class or reflect on their own learning at high school or previous writing classes. In my opinion, this activity could help them to go through some obstacles in writing process. I began thinking of the advantages of keeping a learning diary for students after some semesters of teaching writing. In my diary, I wrote:

I want them to keep a learning diary or journal because I am sure that the diary has functions for learners and teachers. As a teacher I can learn what I have done in my class, especially in my teaching methods. For students, the diary can help them get some ideas for writing. I ask them to do free writing or listing or whatever exercise they want to do to generate ideas. Researchers (Carroll and Bailey) in academic writing have argued that having a diary is a good idea because it helps them learn in class. However, I am in doubt that students will do what I ask because keeping a diary will certainly give them an extra work to do. I can say this because that is what I feel as I keep my own teaching diary. Having to write something in my diary initially is a torture, but gradually it becomes an addiction because I want to improve the way I teach. I hope that my students can feel the same way I do. The diary is due every two months so that I can know their progress. 
It was not easy to start a learning diary for students because it was an extra work. I told them that this was for their own sake, not mine; I was not going to mark it. However, I was happy to give comments on what they had written if they asked me to do so. By asking them to keep a personal diary, I wanted to show that it could be one of the ways to get some good writing ideas. When I read some of the diaries, I found that they struggled to generate ideas for their writing; some of them were frustrated, others were glad because they could finally find the topics. One of them, Erika, (not the real name) wrote that I should give students freedom to write whatever they want, and should not limit on literature, linguistics and cultural studies. She finally asked, "Why is there no freedom in this class?" To her question, I wrote in her diary that she had to learn to write topics outside her "personal territory". Another student, Tony (not the real name) said that the diary could be faked by the students, and the teacher did not know about it. To this, I wrote, "You are right I wouldn't know, but I am happy that I can still write something in your journal that encourages you and your friends to read and write".

Some other students did say that the diary gave them positive things relating to generating ideas. They said that the journal help them remember what they thought yesterday and compared it to what they found today. They also tried to do a free writing for several topics that they thought they could do. I concluded that students had, at least, tried to put general ideas on the paper and did free writing about them. They would know which of these ideas that worked for them, and if they found one, they could develop for their research. Towards this, I wrote:

It seems that students begin to get what they want to write. I agree that it is not easy to write about a topic that they are not familiar with. Subjects such as literature, linguistics/language studies and culture are perhaps not what they expect to write; they probably want to write their personal experience. However, they should write it because they are students of English Departments. Is this kind of enforcing? I don't think so. In one sense, it is one way to teach them about language and culture as a discipline. If they have an intention to become a student of English department, this is what they should learn. So far, learning diary has given them something useful, helping them to see if they could write on a particular topic. 
Apart from keeping a learning journal, I also asked students to read scientific journals in the library, made a copy of an article that interested them and encouraged to discuss it with me in class. In fact, I had them bring some journals in the second day of our meeting and had a discussion about the journals. The idea of class discussion was worth doing because it was a place to share and exchange ideas between the teachers and the students. However, it seemed to me that the idea of reading research journals was still alien to them. I wrote like this:

Research journals seemed to be far from student's interest. But I do not see other ways for our goals in the research writing class. I agree that reading research journals is a must because one advantage is to be able to read some potential research topics that can be developed for their own projects. The problem is how I should be able to persuade and teach them to journals. Research journals are not popular readings, after all. Journals contain scientific and formal writing; things that students do not generally find in their daily readings. The challenge for teachers is to find ways that can make journals part of student's learning agenda.

I should admit that my attempt to teach my students research journals failed to interest them. The long, scientific articles and often contained debates on some specific problems by scientists could only attract students' attention for a short time. This perhaps was related to the problem in teaching the research journal in class; my problem in teaching research journals was to get balanced between explaining the research content and the genre rhetoric. One of the solutions was by bringing several research journals such as Guidelines (published by RELC Singapore), TESOL Quarterly (by TESOL Inc.) and k@ta (by English Department, Faculty of Letters, Petra Christian University) into the class and discussing some articles in it.

\section{Making a Thesis Statement}

Thesis statement or topic sentence is the distinctive mark of an academic essay. A thesis statement contains the main point or central idea of an essay writing which is explicitly stated generally near the end of an introductory paragraph (Leki, 1995, p. 78). While a thesis statement is the central thought of an essay, a topic sentence specifically represents the 
main idea of a paragraph. Leki (1995, p. 81) states that a thesis statement should be general enough to contain the thoughts of the essay, but also specific enough to give the reader a clue on where the essay will be directed. In an argumentative (research) essay, however, its thesis statement should strongly reveal the central idea and its author's voice. The author's voice is a sign of the author's presence throughout the essay. This is an important thing to remember because the essay will make a claim on something and persuade readers to agree with certain opinion. The thesis statement of an argumentative essay reveals the "the author's personal attitudes" (Langan, 2001, p. 296) or views about a problem. Because of such nature, argumentative essays are often debatable or controversial in their contents.

The problem that emerged in my class was how to enable students to express their personal voice in an argumentative thesis statement. "Be brave and personal" to argue on a case were perhaps the key words that I always tried to have in mind when the class talked about how to make a thesis statement. What I found was that students tended to write a thesis statement in a weaker tone, not strong, for their argumentative essays. Thesis statements such as "There are several ways to make..., There are many interesting things about......, There are some interesting conflicts in the play..." represent an explanatory rather than argumentative essay; such thesis statements are describing, not arguing on a case. While the statements are general and specific enough, they do not have the strong author's voice that could really represent the author's argumentative stance. I wrote in my teaching diary:

After several years teaching writing, the problem in making a thesis statement is that we perhaps lack of knowledge of what the author's voice or attitude is, have no idea what we personally want to say and, if we know what we want to say, we lack of method on how we should say it. One should perhaps make a study on the possibility of cultural interventions, too (are we afraid of being judged?). If this is indeed culturally related problem, the challenge for me is not only to teach how technically write a thesis statement, but also encourage students to be brave. Making an argumentative thesis statement needs confidence and evidence on the author's side.

The method that I used to teach students in my class to write a thesis statement was to have them write their own and had an individual or class 
discussion. I also wrote some examples on the board and discussed them with students. I found that such a method was helpful as it could help students with their thesis statement. Through the discussion, fellow students could contribute ideas to improve a thesis statement. Another method that I tried was through free writing in students' learning journal. The idea of free writing in learning journal is a method which pushes students to come closer to finding their own voice as authors. Students are then asked to look back on their free writing to identify patterns, word choices, structural similarities or rhythms.

A problem that was also concerned thesis statement was that some students thought they did not have to write a thesis statement because they still did not know the direction that their essay took. "What if I change my mind in the middle of my essay? Should I change my thesis statement?" they asked me. Toward this problem I would ask why they changed their mind, and a preliminary and explicit thesis statement would be a good idea as it could guide their writing and give a control. However, I also told them not to be hesitant to change their thesis statement if it was necessary because the function of thesis statement, among other things, is to make the writing and reading of an essay easy and smooth for both the writer and reader.

\section{Structuring the Essay}

The next area of concern is in structuring an essay, particularly its body which forms the discussion section. Writing a long research essay is always a problem for students because they have to have a topic and be a critical observer about it, so that they can write it. As I began to discuss the research essay assignment with my students, I was often faced with a question: "Should I also discuss about the essay parts such as the introduction, body and conclusion or, rather, focus on helping my students with the research content?” I debated this in my diary:

I pay attention to how students structure their essay. An essay consists of introduction, body and conclusion. I expect that my students understand about it and look at the previous writing class materials if they need to refresh on that idea. This will give me more time to concentrate to the research content because it is the essence of research writing class. The research content refers to the topics that students will do; based on my experience, students need more help in discussing 
what they want to write. I have a plan that since our first meeting, I will leave the discussion of the essay structure to them and opt to talk about the individual research topics. However, I was held on from doing my plan as two of my students came to my desk and asked what they had to write in the introduction and body. I explained shortly about what they had to do and advised them to open their previous materials. On my way back home, I have a doubt if I could do my plan as I also think of others who might be weak students in my class.

It was true; some students in my class asked me to explain what they had to write in the introduction, body of the essay and conclusion. In the previous semester, I did not explain those parts of essay because I trusted students to work on it by themselves. However, when I read their final essay, I found that students made the introduction, body and conclusion, but except for the conclusion, the parts lacked of patterns and examples or evidence. I made this as an important point that needs to get more attention from me as well as my students. My discussion with students in the present class also helped me to realize that I had to give attention to two "main" parts, introduction and discussion, of an essay which seemed to put them into difficulties. As we went through several meetings, the discussion section was, in fact, found to be the most difficult part of an essay for my students because they had to analyze the problems and present their arguments supported by examples or evidences.

In my next meeting, I focused to explain the methods to make an introduction, referring to patterns of introduction such as the "turnabout", "dramatic entrance", "relevant quotation" and "funnel" (Smalley, Ruetten, \& Kozyrev, 2004, p. 91). I asked them to write an example for each of this pattern and consider which worked for their essay. A week later, I asked them again if they had selected what pattern of introduction they used and I wanted to hear the reasons behind such a selection. Most of them, I found, used the "funnel" which means that the ideas progress from the general to specific; the author starts with a general idea about the topic and works to a specific thesis statement near the end of the part. Unfortunately, I did not hear the reason why they liked using such a pattern for the essay. One of the students who studied a popular sitcom used the "relevant quotation" in her introduction. According to her, the quotations were important because they described the story and the conflicts among its characters; she now wanted to use the quotations in her essay to catch the reader's attention. In helping them to structure the discussion part, I reminded them about 
patterns of rhetorical tools such as cause and effect, providing examples, comparison and contrast, description, process and solution. The decision to use one or combine these patterns depended on the purpose of their essay; whether they wanted to analyze the problem by comparing and contrasting, examining cause and effect, describing the process, making a classification or division etc. Students had to decide on the rhetoric (and its effects to the reader) that they would use in the discussion; it was an individual decision. It was also important for them to have reasons why they, for example, preferred cause and effect to comparison and contrast, or why they decided to combine some of them. When I read their final essay, I wrote:

Students used one or combined rhetoric in their essays. The discussion part of an essay is perhaps not easy because the writer has to make some choices in order to discuss a problem. The choices bring with them some consequences for the reader. I am always reminded by the fact that we write an essay in a way that has to catch the attention of our reader. In an argumentative essay like this, one should remember that he or she has to convince the reader. The use of certain type of rhetoric can bring certain effect to the reader, and this is something that the teacher and the student should know. The challenge for the teacher is to find ways to explain the reasons and consequences behind the use of a particular rhetoric tool. It is important to explain that so that students understand what they choose. When Fanny (not the real name) told me that she wanted to write why Indonesian teenagers prefer western to Indonesian movies, I discussed with her on the use of comparison and contrast in her discussion as she had to explain their characteristics.

Such a reflection led me to think of ways that I could use to explain how the discussion section of an essay should be worked out. While I kept trying to find such methods, I used writing conferences to talk about the functions of rhetorical tools. By doing so, I could discuss with students about particular tools that fitted their research purpose.

\section{Writing Conferences}

One of important activities in the writing process is writing conference. Reid (1995) defines writing conference as "a face to face conversation between the teacher and the student, usually outside the boundaries of the classroom” (p. 220). The importance of writing conference lies in its nature 
which is an event where both parties sit together and, through a dialogue, they discuss the student's individual problems in essay writing. The teacher's responsibility is to listen to what the students talk about their essays and offer thoughts or possible solutions. Writing conference is not only an event where the teacher and the students talk about their writing progress, but also a place to encourage them to be responsible for their writing. Therefore, writing conference should become one of the main activities in writing class. However, such a plan often did not always work well in my class as I expected it to be because only few students realized its importance for them. I wrote about this in my teaching diary:

Writing conference is worth doing because it gives advantages for me and my students. For the teacher, it is an opportunity to see how he or she has done something through the teaching, and for the students, it is to see their writing progress. Like what we have in the last two weeks; so far, the most frequent complaint is about how to generate an idea and develop it into writing. One of the students came to me this morning because she wanted to ask if she could change her topic. I said that the time in which I gave students to shift topics have been over; the mid term period has passed. She has to continue using her present topics. She said that she has no confidence doing her topic because she did not know how she has to do it. Her topic was cross cultural experience of two Indonesians who live abroad and two Americans who live in Indonesia. I told her that her topic was interesting and popular, and I am sure that she could get many references for her writing. I feel that she needs to be assured that her topic was okay and the most important thing here was that I have said “yes, it’s fine topic, you should go ahead. I'm okay with your topic”.

A problem that often happens in writing conference is that it does not become a place where the teacher and the student can discuss and exchange point of view. Reid (1995, p. 220) argued that writing conference is a "negotiated teaching event" where a dialogue should happen between two parties. In many circumstances, it should be a valuable event of learning where the student can "take control" the interaction, negotiating meaning and clarifying the teacher's response. That was, unfortunately, not what happened in my class because the students came to the conference, mostly to ask my permissions upon what they would be doing with the topic. While I often did not object to their plan, I was bothered by the fact that the real interaction between my students and I often did not happen in 
our conference; it was supposed to be a meaning or idea negotiation. When we met in a writing conference, the most frequent type of questions which my students asked were a kind of close question that only needed me to say "yes" or "no". In other words, I felt that they treated me as if I were the authority in the class that could allow them to do this and not that. In relation to this problem, I wrote:

I feel that this conference has no result if I just said "yes" or "no" to them. I do not know the reason why they do this or that. In one sense, such a short and asymmetrical interaction liberate me from having to do my responsibility as a teacher which is to give them different perspective or solution upon their research topic. However, I think that I might regret at the end of the semester that these students could have done something better if I gave them different perspectives, no necessarily mine; they have options to choose to improve their work. To make the writing conference such a valuable event for the students and me, I changed the style of conversation. In the beginning of the conference, I allow them to ask me their questions, but then I will return their questions, using, mostly, the "why" and "how" questions. There are two advantages that I can obtain through such a "method"; one is that I can make us "talk" in a way that the conference was supposed to be and, second, my question will push the students to reflect upon what they have done. They should be, after all, an independent learner at university.

When I tried to implement this idea, I still faced the same problem and the discussion did not work as I expected. It seemed to me that now the difficulty came from the kind of questions that I asked to my students. However, I still saw that it could work for some students only if I gave enough time for the conference to work for both sides. The key to this problem was perhaps on how much time we could spend for the conference to create a good dialogue between my students and me.

\section{IMPLICATIONS FOR TEACHING WRITING}

There are implications that I make based on such reflections. First, I find that the early step in research writing, especially in generating ideas is important to determine the continuity of writing process. More attention should be paid to how these ideas can be generated and further explored so 
that students can find the most appropriate research topic for them. I find that by keeping learning journal, students can actually know on paper whether their ideas work; at the same time, the learning journal will also help students to become independent learners because they would be able to determine what works for them. I also find that classroom discussions and scientific research journals help me to provide my students with ideas for research topics. Second, frequent classroom discussions on general topics followed by specific written exercises are necessary to enable students to produce a strong argumentative thesis statement. Classroom discussions and conferences give students a chance to discuss their personal views on a subject, and only if teachers make it explicit in specific exercises can students analyze and write a thesis statement. Third, in relation to structuring the essay, especially in the discussion section, an outline can be very helpful. Although the outline is preliminary, it is a writing plan that will guide the students to determine the direction and development of the discussion. And fourth, writing conference is crucial as it provides students with feedbacks or clarifications. More attention should be given to the importance of this event and on how to make it beneficial for both the teacher and the student. Reid (1995, p. 220) lists several points that can make a writing conference counterproductive to its advantages, and writing teachers should act to reduce such negative impact.

\section{CONCLUSION}

The decision to use a teaching diary began as an attempt to help me improve my teaching. Looking back on what I did to help my students to generate ideas, make a thesis statement, structure an essay and provide with input through writing conferences, I can see the strength and weakness in my decision. In general, my reflection suggests that more individual time and space should be provided in class to accommodate and clarify thoughts from the student and teacher. As the result of my reflection, for instance, I have made a change in my teaching strategy, and that is to provide considerable time for writing conferences. It is an effective method through which I can talk to my students individually about their writing and make some specific suggestions about it. I also should let students to have more control during the writing conferences as it might be the most comfortable place for them to express their thoughts about the essays. Generating ideas can be very useful when students do it through free writing in a learning 
journal. At the same time, students' learning journal is also a good tool for teachers to understand the problems that students are facing in the class assignment. Finally, keeping a professional diary helps me to reflect on what I have done in my writing class. There is a chance to analyze some teaching decisions that I have made and redefine my teaching strategies and philosophy for professional development. In one way or another, my teaching diary has been acting as my "shadow" mentor who guides me in questioning my teaching assumptions and finding ways to resolve problems.

\section{REFERENCES}

Alexander, N. (2001). A long day's journal into night: a primer on writing dialogue journal with adolescent ESL students. In J. Burton, \& Carroll (Eds.), Journal writing (pp. 23-35). Washington: TESOL Inc.

Bailey, K.M. (1990). The use of diary studies in teacher education program. In J. C. Richards, \& D. Nunan (Eds.), Second language teacher education (pp. 215226). Cambridge: Cambridge University Press.

Bartlet, L. (1990). Teacher development through reflective teaching. In J. C. Richards, \& D. Nunan (Eds.), Second language teacher education (pp. 202214). Cambridge: Cambridge University Press.

Boonmoh, A. (2005). Getting ready to teach in a large class: A diary study. Guidelines, 27, 14-18.

Burton J., \& Carroll, M. (2001). Journal writing as an aid to self-awareness, autonomy, and collaborative learning. In J. Burton, \& M. Carroll (Eds.), Journal writing (pp. 1-7). Washington: TESOL Inc.

Carroll, M. (1994). Journal writing as a learning and research tool in the adult classroom. TESOL Journal, 4(1), 19-22.

Carroll, M., \& Mchawala, C. (2001). Form or meaning? Academic writing with a personal Voice. In J. Burton \& M. Carroll (Eds.), Journal writing (pp. 4758). Washington: TESOL Inc.

Gorman, D. (1998). Self-tuning teachers: Using reflective journals in writing classes. Journal of Adolescent \& Adult Literacy, 41(6), 434-442.

Halliday, M. (1985). Spoken and written language. Geelong: Deakin University Press. 
Leki, I. (1995). Academic writing: Exploring processes and strategies. New York: St. Martin Press.

Menasche, L. (1997). Writing a research paper. Michigan: The University of Michigan Press.

Mezirow, J. (1991). Transformation theory and social action. Adult Education Quarterly, 39, 169-175.

Norton, B. (2000). Identity and language learning: Gender, ethnicity and educational change. London: Pearson Education.

Numrich, C. (1996). On becoming a language teacher: Insights from diary studies. TESOL Quarterly, 30(1), 131-151.

Nunan, D. (1991). Language teaching methodology: A textbook for teachers. New York: Prentice Hall.

Porter, P. A., Goldstein, L. M., Leatherman, J., \& Conrad, S. (1990). An ongoing dialogue: Learning logs for teacher preparation. In J. C. Richards \& D. Nunan (Eds.), Second Language Teacher Education Cambridge (pp. 227240). Cambridge University Press.

Reichmann, C. L. (2001). Teachers in dialogue: Exploring practice in an interactive professional journal. In J. Burton, \& M. Carroll (Eds.), Journal writing (pp. 125-135). Washington: TESOL Inc.

Reid, J. (1993). Teaching ESL writing. New Jersey: Regents/Prentice Hall.

Richards, J. C., \& Farrell, T, S. C. (2005). Professional development for language teachers: Strategies for teacher learning. Cambridge: Cambridge University Press.

Richards, J., \& Lockhart, C. (1994). Reflective teaching in second language classrooms. Cambridge: Cambridge Language Education Series.

Schon, D. (1987). Educating the reflective practitioner. California: Jossey-Bass.

Smalley, R. L., Ruetten, M. K., \& Kozyrev, J. R. (2004). Focus on writing. Singapore: Thomson Learning.

Zamel, V. (1982). Writing: The process of discovering meaning. TESOL Quarterly, 16(2), 195-209. 